\title{
Response of a Predatory Insect, Chrysopa sinica, toward the Volatiles of Persimmon Trees Infested with the Herbivore, Japanese Wax Scale
}

\author{
Yanfeng Zhang, Yingping Xie, Jiaoliang Xue, Xingen Yang, and Sha Gong \\ College of Life Science, Shanxi University, Taiyuan 030006, China \\ Correspondence should be addressed to Jiaoliang Xue, xuejl@sxu.edu.cn
}

Received 31 July 2011; Revised 15 December 2011; Accepted 8 February 2012

Academic Editor: Andrew Sih

Copyright (C) 2012 Yanfeng Zhang et al. This is an open access article distributed under the Creative Commons Attribution License, which permits unrestricted use, distribution, and reproduction in any medium, provided the original work is properly cited.

\begin{abstract}
A predatory insect, Chrysopa sinica Tiedet (Neuroptera: Chrysopidae), and its taxis behavior were investigated in a tritrophic system that included a herbivore, Ceroplastes japonicus Green (Hemiptera: Coccidae), and a host plant, persimmon tree, Diospyros kaki L. (Ebenaceae). The results showed that this predator was attracted to the volatile compounds of persimmon trees that were infested with C. japonicus; however, the attraction varied with the growth season of the trees and the development stage of the wax scale. The strongest attraction occurred in the autumn and not in the late spring or summer. For the four time periods considered throughout the day, the most significant attraction rates were found at midnight and the early afternoon. The results indicated that the transformation of the chemical compositions of the volatiles of the persimmon tree might drive the taxis response of the predator in the three studied seasons. We mainly found differences in terpenoid emissions and propose that these compounds play a key part in the observed differences in attractiveness.
\end{abstract}

\section{Introduction}

Persimmon, Diospyros kaki L. (Ebenaceae), is an important fruit tree species in Northern China where orchards cover approximately 73,400 ha. Japanese wax scale, Ceroplastes japonicus Green (Hemiptera: Coccoidea: Coccidae), is one of the most destructive insect pests in persimmon orchards. The population of this scale insect is generally so dense in persimmon orchards that there are approximately 32 scale individuals on twigs $(10 \mathrm{~cm}$ long) and 200 scale individuals on each leaf. Causing a reduction of approximately $70 \%$ of the fruit yield annually, the insect damages the persimmon trees by sucking the sap, which reduces plant vigor, and by excreting honeydew from its anus, which pollutes the plant surface and simultaneously induces leaf mold [1]. The scale insect secretes a mass of waxy substances through integument wax pores that creates a wax covering on its cuticle, and due to the protection that this wax covering confers, the efficacy of pesticide sprays has been limited. In practice, the frequent application of chemical pesticides leaves toxic residues on the fruit, produces environmental pollution, and causes the death of the natural enemies of the scale [2]. Therefore, using parasitoids and predators as biological agents to control the scale insect is a more sustainable alternative [3].

In our investigation, two species of green lacewings, Chrysopa septempunctata Wesmael and Chrysopa sinica Tiedet (Neuroptera: Chrysopidae), were found to be the primary predators for controlling Japanese wax scale in persimmon orchards in Northern China. Both the lacewing larvae and adults prey on the Japanese wax scale's eggs, nymphs, and adults. Under natural conditions, however, the population levels of green lacewings are not stable in orchards because the lacewings often fly away from the area, thus reducing the efficacy of biological control. Another problem is that the green lacewings do not always emerge during the season when the scale infestation occurs and generally enter the infested orchard after the scale insect has already caused damage.

Some studies have shown that herbivores can induce host plants to produce a defense response via the synthesis and release of complex mixtures of volatile compounds that 
mediate the attraction of predators and/or parasitoids of the herbivores to the damaged host plants [4-10]. Such herbivore-induced plant volatiles (HIPVs) may serve as cues that help the natural enemies of those herbivores to locate their prey [11-16].

Our objective in the present study was to investigate the role of volatile emissions of persimmon trees, either infested with scale insects or not, in attracting the predator, Chrysopa sinica, by comparing the predator's response to the volatiles. Our goal was to provide new ideas for the biological control of scale insects, based on the cooperative application of predators and semiochemicals emitted by host plants.

\section{Materials and Methods}

2.1. The Orchard Conditions and Experimental Period. The experiment was conducted in two persimmon orchards located in the Linyi County of Shanxi Province in Northern China (lat. $35^{\circ} 40^{\prime} \mathrm{N}$, long. $111^{\circ} 27^{\prime} \mathrm{W}$, elev. $700 \mathrm{~m}$ ). The persimmon trees in the orchards were 2 years old and approximately $1.5 \mathrm{~m}$ in height and $1.0 \mathrm{~m}$ at the crown width. One orchard suffered much higher damage by herbivores than the other orchard. The damaged orchard was approximately $1 \mathrm{~km}$ away from the undamaged one. The uniform persimmon trees of the two orchards were planted in the same year, and the two orchards were grown on the same soil type and under the same climate conditions. In a preliminary experiment, we compared the attraction of undamaged persimmon leaves from the damaged orchard versus the undamaged orchard by Y-tube olfactometry. We found no difference in the number of green lacewings that responded to the two undamaged leaves obtained from the different orchards. The experiment was carried out from May to October, a period during which the Japanese wax scale, Ceroplastes japonicus Green, exhibited three feeding periods that caused damage on persimmon trees. The first period occurred in May and June when female wax scale adults fed voraciously to prepare for their oviposition and while the persimmon trees were developing into anthesis. The second period was in July and August, when much of the damage occurred due to leaf sucking by first- and second-instar scale nymphs. During this phase, the nymph population often reached a maximum of 200 individuals on each leaf in the seriously damaged orchard. The third period, September and October, was characterized by the new adults mating and moving from leaves to twigs. During this phase, the average number of insects was 32 per $10 \mathrm{~cm}$ long twig, and more than $70 \%$ of the branches were infested, as female adults fed and stored sufficient nutrients to prepare for the following winter.

2.2. Source of Predators. Chrysopa sinica Tiedet was selected as the predator for testing the tropism response to the volatiles from the persimmon trees that were infested (or noninfested) with the wax scale. The predators were collected and held temporarily in a clean glass tube with water and fresh wax scales as a food source. The adults used for the olfactometry experiments were starved for $12 \mathrm{~h}$ before the test.
2.3. The Response of Predators to Different Odor Sources. A Y-tube olfactometer was used to test the 2-choice response of $C$. sinica to volatiles from damaged versus undamaged persimmon in one experiment, and their responses were compared at four times of day in another experiment. The olfactometer consisted of a Y-shaped glass tube $(2.5 \mathrm{~cm}$ in diameter), with a base that was $20 \mathrm{~cm}$ long and each of the two arms was $13 \mathrm{~cm}$ long. The angle between the two arms was $60^{\circ}$, and each arm was connected to a glass cylinder $(7 \times 16 \mathrm{~cm})$ in which $15 \mathrm{~g}$ of leaves and twigs were used as the source of volatile compounds. Whole leaves were cut from the plant before the experiment, and the petioles were wrapped in wet cotton and aluminum foil. An airstream was passed through a tube containing active charcoal and a humidifier bottle. The tube was divided into two parts, and each secondary airstream was directed to one of the glass cylinders at a flow rate of $200 \mathrm{~mL} / \mathrm{min}$. During the experiments, the temperature was maintained at $25-28^{\circ} \mathrm{C}$, and the olfactometer was placed under an artificial light source consisting of one $30 \mathrm{~W}$ fluorescent lamp.

Persimmon leaves were collected from representative trees and used as the volatile source immediately after collection. At the start of each test, 10 adults of $C$. sinica were introduced into the base of the olfactometer tube and given $10 \mathrm{~min}$ to respond. A positive choice was recorded if a green lacewing crawled further than $1 / 3$ of the length of the $Y$ arm leading to the volatile source and remained there for at least $1 \mathrm{~min}$. If a green lacewing did not move toward the volatile source within $10 \mathrm{~min}$, it would be recorded as no response. To eliminate the effects of asymmetrical bias, we exchanged the connections of the two arms of the olfactometer to the cylinders after each test. After two tests, the olfactometer tube was washed with $95 \%$ alcohol and heated for several minutes to dry; the cylinders were then changed, and a new set of leaves was used. During each of the three 2-month feeding periods, the test was repeated with six groups of insects each day for three successive days. Different adults of C. sinica were used in each replication.

During the third period in September, to test whether the response of the green lacewings varied at different times of the day, we conducted tropism response tests at four times during a whole day as follows: from 1:00-3:00, 7:00-9:00, 13:00-15:00, and 19:00-21:00. Each test at four times during a whole day also was repeated six times for three successive days. In addition, the other experiment was conducted to test whether the wax scale itself could attract the green lacewings. Therefore, the wax scale itself as odor source compared with undamaged leaves and twigs. And the odor sources of volatiles from damaged leaves and twigs with no wax scales versus volatiles from undamaged leaves and twigs were compared; these works were carried out at 13:00-15:00 that wax scales were removed 3-6 hours earlier. The same as above, the test was repeated with six groups of the green lacewings each day for three successive days.

2.4. Collection and Analysis of the Volatiles. A headspace, volatile-trapping instrument was used to collect the volatiles from the persimmon trees. An atmospheric sample collector 
(model QC-1S, Beijing Labor Protection Institute Co. Ltd., Beijing, China) was used to draw and control the airflow through the volatile collection bag $(80 \mathrm{~cm}$ in length, $45 \mathrm{~cm}$ in diameter). Each bag enclosed one sampled branch that had approximately 120 leaves. Air entered the bottom of the bag through an air-filtration tube to keep the air clean and dry, passed through an absorbent trap (Porapak Q, 80-100 mesh) (Alltech Deerfield, IL, USA), and exited out through the bag. In the volatile collection process, the airflow rate was controlled at $100 \mathrm{~mL} / \mathrm{min}$ through the trap. The collection time for each volatile sample lasted 4 hours, and each treatment was repeated 5 times.

After collection, the traps were eluted with $1 \mathrm{~mL}$ of gas chromatography/mass spectroscopy (GC/MS) analytical grade methylene chloride (Lichrosolv; Merck, Whitehouse Station, NJ, USA). A light stream of charcoal-filtered air was used to force any residual methylene chloride through the trap. The eluate was concentrated to $300 \mu \mathrm{L}$ under a stream of compressed nitrogen; and $40 \mathrm{ng}$ n-octane in $10 \mu \mathrm{L}$ methylene chloride was added to each eluted sample as an internal standard. We analyzed the chemical compounds of the volatile samples using a gas chromatograph/mass spectrometry (GC/MS) (Trace 2000 GC) equipped with a DB-5 MS/LB column $(30 \mathrm{~m} \times 0.25 \mathrm{~m} \mathrm{ID}, 0.25 \mu \mathrm{m}$, Dikma, USA) with $1.0 \mathrm{~mL} / \mathrm{min}$ helium as the carrier gas. The splitless mode injector system was set at $220^{\circ} \mathrm{C}$, and the column temperature was maintained at $40^{\circ} \mathrm{C}$ for $3 \mathrm{~min}$ and increased at a rate of $5^{\circ} \mathrm{C} / \mathrm{min}$ to $100^{\circ} \mathrm{C}$, which was maintained for $10 \mathrm{~min}$, and then increased at a rate of $20^{\circ} \mathrm{C} / \mathrm{min}$ to $290^{\circ} \mathrm{C}$ for $4 \mathrm{~min}$. The compounds within the volatiles were identified by comparison of their retention times and mass spectra to those contained in the standards database of NIST/EPA/NIH Mass Spectral Library (Scientific Instrument Services, Inc., USA).

2.5. Statistical Analyses. Differences in the responses of $C$. sinica to the odor sources were analyzed using the $t$-test. The data for the every volatile compound of 2 treatments in each month was analyzed using paired samples $t$-test (SPSS V12.0, SPSS Inc.).

\section{Results}

3.1. Response of C. sinica. The experimental results (Table 1) showed that, although the Japanese wax scale caused damage from late spring to late autumn, the persimmon trees' responses may be different than what was indirectly displayed by the tropism response of the predatory insect, $C$. sinica, to the volatiles emitted by the persimmon trees. In late spring to early summer, the female adults of the Japanese wax scale fed on and damaged the twigs of the persimmon trees. In May, predators did not respond differently to damaged versus undamaged plants. From July to August, the Japanese wax scale developed into its nymph stage, and a large number of the nymphs were settling and feeding on the leaves. The experiment in July on the tropism response of $C$. sinica to the volatiles emitted by the persimmon trees showed a result that was very similar to May.
In September, the situation was markedly changed, as the wax scale developed into the adult stage, and adult females fed voraciously on the persimmon trees. In the tropism response experiment of the green lacewings to the different odor sources from the persimmon trees, a larger number of C. sinica moved toward the persimmon leaves with wax scale damage than toward the undamaged leaves. In a four timephase experiment conducted on a single day, the predators showed stronger taxis responses to the volatiles from the damaged persimmon leaves at two time phases, early morning (1:00-3:00) and early afternoon (13:00-15:00), with percentages of $67.95 \%$ and $66.67 \%$, respectively, which were significantly different from the random expectation of $50 \%$ $(P<0.01$ and $P<0.05)$. In comparison, at 7:00-9:00 and 19:00-21:00, there was no significant difference tendency for C. sinica to be attracted to damaged leaves.

Furthermore, we found that the Japanese wax scale itself and the leaves and twigs of the damaged trees which the insects were removed from 3 or 6 hours before the experiment also attracted the predators (Table 2); the differences were significant $(P<0.05)$ when compared with the undamaged odor sources. However, the green lacewings preferred the mixture of volatiles from damaged persimmon tree leaves and twigs and Japanese wax scales $(66.67 \%$, showed in Table 1).

\subsection{Volatile Emission of Persimmon Trees in Different Seasons.} During the periods of development and infestation of the Japanese wax scale (the female adults in May and June, the young nymphs in July and August, and the new generation of adults in September and October), the persimmon trees completed their anthesis in late spring and early summer and fruited in the summer season, with fruit ripening in autumn. During these different stages, the volatiles of the trees changed in their composition and emission levels due to the wax scale damage.

By collecting the volatiles of the experimental trees in the three stages and analyzing the chemical compositions using GC/MS, we detected a total of 30 compounds. These compounds may be classified into five different groups: terpenoids comprising 13 compounds, 2 alcohols, 1 ester, 2 aldehydes, and 12 hydrocarbons. Of these, the terpenoids, alcohols, and esters should be especially noted for their critical roles in natural enemy attraction [17, 18]. Table 3 shows the changes in the volatile samples in May, July, and September. In May, two terpenoid compounds were detected from the undamaged persimmon trees, whereas seven terpenoid compounds were detected from the wax-scaledamaged trees, indicating that six terpenoid compounds were novel components produced by the wax-scale-damaged persimmon trees. The results for July were similar: the same two terpenoid compounds were detected from the undamaged persimmon trees, whereas five novel terpenoid compounds were found in the damaged persimmon tree volatiles. In September, only one terpenoid compound was detected in the undamaged persimmon tree volatiles, whereas nine terpenoid compounds, including eight novel ones, were detected in the damaged persimmon tree volatiles. It is 
TABLE 1: The tropic response of C. sinica to persimmon leaves damaged (or undamaged) by Japanese wax scale at four different times of a day.

\begin{tabular}{|c|c|c|c|c|c|c|c|c|c|c|c|c|}
\hline \multirow{2}{*}{$\begin{array}{l}\text { Odor } \\
\text { source }\end{array}$} & \multicolumn{4}{|c|}{ May } & \multicolumn{4}{|c|}{ July } & \multicolumn{4}{|c|}{ September } \\
\hline & Mean & $S^{2}$ & $\begin{array}{l}\text { Tendency } \\
\text { percentage }\end{array}$ & $t$-test & Mean & $S^{2}$ & $\begin{array}{l}\text { Tendency } \\
\text { percentage }\end{array}$ & $t$-test & Mean & $S^{2}$ & $\begin{array}{l}\text { Tendency } \\
\text { percentage }\end{array}$ & $t$-test \\
\hline UD-a & 11.7 & 4.89 & $51.09 \%$ & \multirow{2}{*}{ NS } & 11.7 & 3.92 & $48.94 \%$ & \multirow{2}{*}{ NS } & 8.3 & 1.89 & $32.05 \%$ & \multirow{2}{*}{$* *$} \\
\hline $\mathrm{D}-\mathrm{a}$ & 11.2 & 6.14 & $48.91 \%$ & & 11.2 & 10.0 & $51.06 \%$ & & 17.7 & 6.89 & $67.95 \%$ & \\
\hline UD-b & 11.0 & 7.33 & $49.25 \%$ & \multirow{2}{*}{ NS } & 10.2 & 3.56 & $49.19 \%$ & \multirow{2}{*}{ NS } & 14.7 & 9.22 & $49.44 \%$ & \multirow{2}{*}{ NS } \\
\hline D-b & 11.3 & 11.56 & $50.75 \%$ & & 10.5 & 8.25 & $50.81 \%$ & & 15.0 & 7.33 & $50.56 \%$ & \\
\hline UD-c & 13.2 & 7.47 & $49.07 \%$ & \multirow{2}{*}{ NS } & 13.2 & 4.56 & $47.31 \%$ & \multirow{2}{*}{ NS } & 10.2 & 5.47 & $33.33 \%$ & \multirow{2}{*}{ * } \\
\hline$D-c$ & 13.7 & 4.56 & $50.93 \%$ & & 14.7 & 8.89 & $52.69 \%$ & & 20.3 & 8.89 & $66.67 \%$ & \\
\hline UD-d & 7.8 & 2.81 & $48.96 \%$ & \multirow{2}{*}{ NS } & 9.7 & 2.22 & $51.79 \%$ & \multirow{2}{*}{ NS } & 13.2 & 7.14 & $49.07 \%$ & \multirow{2}{*}{ NS } \\
\hline D-d & 8.2 & 4.81 & $51.04 \%$ & & 9.0 & 4.33 & $48.21 \%$ & & 13.7 & 4.22 & $50.93 \%$ & \\
\hline
\end{tabular}

Notes: UD means undamaged persimmon trees leaves; D means damaged persimmon trees leaves; the following letters refer to the time of a day when the tests were conducted: a (1:00-3:00), b (7:00-9:00), c (13:00-15:00), and d (19:00-21:00); NS, not significant; ** $P<0.01 / 12 ;{ }^{*} P<0.05 / 12$.

TABLE 2: The tropic response of $C$. sinica to Japanese wax scale and damaged persimmon leaves without wax scales.

\begin{tabular}{lcccc}
\hline Odor source & Mean & $S^{2}$ & Tendency percentage & $t$-test \\
\hline UD & 8.8 & 2.47 & $41.41 \%$ & $*$ \\
B & 12.5 & 1.58 & $58.59 \%$ & $*$ \\
\hline UD & 8.3 & 4.56 & $38.16 \%$ & $*$ \\
D-3 & 13.5 & 4.25 & $61.84 \%$ & $*$ \\
\hline UD & 10.5 & 3.92 & $43.45 \%$ & $*$ \\
D-6 & 13.7 & 1.22 & $56.55 \%$ & \\
\hline
\end{tabular}

Notes: UD means undamaged persimmon trees leaves; B means the wax scale body itself; D-3 and D-6 means leaves and twigs of damaged persimmon trees which the insects were removed from for 3 or 6 hours before the experiment; ${ }^{*} P<0.05 / 12$.

interesting that, in the undamaged persimmon tree volatiles, the detected terpenoid compounds were $\beta$-trans-ocimene and $\beta$-cis-ocimene, whereas, in the damaged persimmon tree volatiles, the detected terpenoid compounds contained 3 -thujene, $4[10]$-thujene, $\alpha$-pinene, 2[10]-pinene-[1S,5S]$[-], \beta$-pinene, camphene, limonene, and farnesene. The pattern of the terpenoid compositions in the persimmon tree volatiles throughout the three seasons was relatively stable, with the differences mainly found in the emission level of each compound. In May, July, and September, the terpenoid emission levels from the damaged persimmon tree were $18384 \mathrm{ng} / \mathrm{h}, 2729 \mathrm{ng} / \mathrm{h}$, and $31255 \mathrm{ng} / \mathrm{h}$, respectively. These results indicated that the highest emissions of September should correspond to a significant taxis effect of C. sinica, which was attracted to the volatile sources from the wax scale-damaged persimmon trees. Compared with the other compounds, $\alpha$-pinene, with the highest emission amount of $20223 \mathrm{ng} / \mathrm{h}$, might play a significant role in recruiting the $C$. sinica predator.

Only one species of alcohol, 3-hexen-1-ol, was detected in the persimmon tree volatile samples for May and July, whereas two alcohols were detected in September. The emission levels of the alcohols were markedly higher in the damaged persimmon tree volatiles than in the undamaged tree volatiles.

Only one ester compound, 3-hexenyl acetate, was found in the damaged host volatile samples for July.

\section{Discussion}

It has been reported that herbivores induce host plants to produce an array of volatile organic compounds and that some of these compounds may be used as chemical cues by natural enemies of herbivores to locate of their prey $[6,17-20]$. A similar phenomenon has also been found in the tritrophic system of the host plant, Bunge prickly ash (Zanthoxylum bungeanum Maxim (Rutaceae)), the herbivore, mealybug (Phenacoccus azaleae (Kuwana) (Hemiptera: Coccoidea: Pseudococcidae)) and the predator, ladybeetle (Harmonia axyridis (Pallas) (Coleoptera: Coccinellidae)). In this system, the fresh twigs and leaves of Bunge prickly ash trees damaged by the mealybug attracted the ladybeetles to aggregate, resulting in increasing populations of ladybeetles and decreasing populations of mealybugs in a Bunge prickly ash forest [21].

However, our study found that persimmon trees under attack by Japanese wax scale did not always display an equally attractive effect on the predator, $C$. sinica, during the three different seasons. In May and July, C. sinica showed no significant tendency to be attracted to damaged persimmon leaves or twigs. Only in September did the damaged persimmon trees display a strong attraction effect. The reason for this observation might be that, in May and June, the persimmon trees were rapidly growing due to the florescence stage, with the large transport of nutrients in the sap and rapid expansion of leaf areas, which may have diluted the effect of the wax scale damage despite the old female adults feeding on the twigs. In contrast, the persimmon trees were at a stable growth stage in July and August, and the Japanese wax scale nymphs fed on the leaves and tips of 
TABLE 3: Comparison of volatile compounds (mean \pm SE) detected by GC/MS from wax scale-damaged and undamaged persimmon trees.

\begin{tabular}{|c|c|c|c|c|c|c|}
\hline \multirow{3}{*}{ Compound } & \multicolumn{6}{|c|}{ Emissions (ng/h) } \\
\hline & \multicolumn{2}{|c|}{ May } & \multicolumn{2}{|c|}{ July } & \multicolumn{2}{|c|}{ September } \\
\hline & UD & $\mathrm{D}$ & UD & $\mathrm{D}$ & UD & $\mathrm{D}$ \\
\hline \multicolumn{7}{|l|}{ (I) Terpenoid compound } \\
\hline 3-Thujene & $0 \pm 0$ & $2090 \pm 321^{* *}$ & $0 \pm 0$ & $133 \pm 59$ & $0 \pm 0$ & $6071 \pm 2530^{* *}$ \\
\hline $4[10]$-Thujene & $0 \pm 0$ & $1053 \pm 192 *$ & $0 \pm 0$ & $22 \pm 8$ & $0 \pm 0$ & $1445 \pm 629$ \\
\hline$\alpha$-Pinene & $0 \pm 0$ & $3660 \pm 510^{* *}$ & $0 \pm 0$ & $262 \pm 104$ & $0 \pm 0$ & $20223 \pm 6842^{* *}$ \\
\hline $2[10]$-Pinene- $[1 S, 5 S]-[-]$ & $0 \pm 0$ & $343 \pm 55^{*}$ & $0 \pm 0$ & $0 \pm 0$ & $0 \pm 0$ & $0 \pm 0$ \\
\hline$\beta$-Pinene & $0 \pm 0$ & $1550 \pm 356^{*}$ & $0 \pm 0$ & $115 \pm 56$ & $0 \pm 0$ & $2207 \pm 1300^{*}$ \\
\hline Camphene & $0 \pm 0$ & $0 \pm 0$ & $0 \pm 0$ & $0 \pm 0$ & $0 \pm 0$ & $511 \pm 243^{*}$ \\
\hline Limonene & $0 \pm 0$ & $3610 \pm 996^{*}$ & $0 \pm 0$ & $191 \pm 71^{*}$ & $0 \pm 0$ & $623 \pm 307^{*}$ \\
\hline$\beta$-trans-Ocimene & $847 \pm 374$ & $6078 \pm 1350^{*}$ & $178 \pm 65$ & $787 \pm 316$ & $0 \pm 0$ & $89 \pm 47$ \\
\hline$\beta$-cis-Ocimene & $1817 \pm 404^{*}$ & $0 \pm 0$ & $2481 \pm 844$ & $1219 \pm 573^{*}$ & $2147 \pm 932$ & $32 \pm 11$ \\
\hline Farnesene & $0 \pm 0$ & $0 \pm 0$ & $0 \pm 0$ & $0 \pm 0$ & $0 \pm 0$ & $54 \pm 22$ \\
\hline \multicolumn{7}{|l|}{ (II) Alcohol compound } \\
\hline 3-Hexen-1-ol & $482 \pm 115$ & $1683 \pm 398^{*}$ & $0 \pm 0$ & $385 \pm 196^{*}$ & $0 \pm 0$ & $400 \pm 124^{*}$ \\
\hline 2-Ethyl-1-hexanol & $0 \pm 0$ & $0 \pm 0$ & $0 \pm 0$ & $0 \pm 0$ & $638 \pm 291$ & $1503 \pm 667$ \\
\hline \multicolumn{7}{|l|}{ (III) Ester compound } \\
\hline 3-Hexenyl-acetate & $0 \pm 0$ & $0 \pm 0$ & $0 \pm 0$ & $234 \pm 110$ & $0 \pm 0$ & $0 \pm 0$ \\
\hline
\end{tabular}

Notes: UD means undamaged persimmon trees leaves; D means damaged persimmon trees leaves; ${ }^{*} P<0.01 ;{ }^{*} P<0.05$.

twigs. Therefore, the damage by the young nymphs may not have been strong enough to completely activate a defense response, resulting in the volatiles of the damaged trees demonstrating a weak attractive effect on C. sinica. However, when the persimmon trees were going into fruit maturity in September and October, the population of the wax scale adults was dense, averaging 32 and a maximum of 240 scales on a $10 \mathrm{~cm}$ long twig. To accumulate sufficient nutrition for the winter, the wax scale adults fed heavily on the twigs, and the feeding and damage at this stage were the most severe, thus inducing the damaged trees to produce much more volatiles, which stimulated a strong taxis response in C. sinica.

In our study of the tritrophic system consisting of persimmon trees, Japanese wax scale, and C. sinica, the damaged host plants releasing volatiles and attracting the natural enemies were correlated with the herbivore's population density and developmental stages and also with the host plant's growth stage, physiology, and phenology [22]. Clearly, the system is very complex.

Furthermore, our study also found fluctuations of the attractive effect throughout the day, as shown in Table 1, a finding that has been rarely noted in previous reports [23]. In our investigation of the relative humidity and temperature, the two higher response phases of $C$. sinica to the wax scale-damaged persimmon trees appeared at midnight, with the highest $\mathrm{RH}$ and lowest temperature and in the early afternoon, with the lowest RH and highest temperature. The reason for this might be correlated with stomatal movements and the metabolism of the trees, the feeding rhythm of the wax scale, or both. However, further studies are required.
By analyzing the volatile composition from persimmon trees damaged or undamaged by Japanese wax scale, we found that three compounds, terpenoids, alcohols, and esters, were the most potential semiochemicals for attracting C. sinica to aggregate to the damaged persimmon trees. Furthermore, by a comparison of the responses of $C$. sinica, we showed that the primary composition of the volatiles from the trees was $94 \%$ terpenoids, with $\alpha$-pinene and 3 -thujene being dominant, which is similar to others reports that show that terpenoids are the main attractants for natural enemies [24]. In a previous study, we had shown that terpenoids, especially $\alpha$-pinene, were highly attractive to the predator, Chilocorus kuwanae Silvestri (Coleoptera: Coccinellidae) [25]. These findings may have practical applications in the use of semiochemicals to enhance biological control. Other studies are necessary to apply these semiochemicals under simulated biological control conditions.

\section{Acknowledgments}

This project was supported by grants from the National Nature Science Foundation of China (no. 30872034), the Nature Science Foundation of Shanxi Province (20090110412), and the Research Project Supported by Shanxi Scholarship Council of China (2011-009).

\section{References}

[1] Y. P. Xie, The scale insects of the forest and fruit trees in Shanxi of China, China Forestry Publishing House, Beijing, China, 1998.

[2] Y. P. Xie and J. L. Xue, "Ultra-morphology and chemical composition of waxes secreted by two wax scale insects, 
Ceroplastes ceriferus (Fabricius) and C. japonicus Green (Homoptera: Coccidae)," Acta Entomologica Sinica, vol. 48, pp. 837-848, 2005.

[3] R. G. Van Driesche and T. S. Bellows Jr., Biological Control, Chapman and Hall, New York, NY, USA, 1996.

[4] L. E. M. Vet and M. Dicke, "Ecology of infochemical use by natural enemies in a tritrophic context," Annual Review of Entomology, vol. 37, no. 1, pp. 141-172, 1992.

[5] C. M. DeMoraes, W. J. Lewis, P. W. Pare, H. T. Alborn, and J. H. Tumiinson, "Hervibore-infested plants selectively attract parasitoids," Nature, vol. 393, no. 6685, pp. 570-573, 1998.

[6] A. Kessler and I. T. Baldwin, "Defensive function of herbivoreinduced plant volatile emissions in nature," Science, vol. 291, no. 5511, pp. 2141-2144, 2001.

[7] T. C. J. Turlings and F. Wäckers, "Recruitment of predators and parasitoids by herbivore-injured plants," in Advances in Insect Chemical Ecology, R. T. Cardé and J. G. Millar, Eds., pp. 21-75, Cambridge University Press, Cambridge, UK, 2004.

[8] J. G. De Boer, M. A. Posthumus, and M. Dicke, "Identification of volatiles that are used in discrimination between plants infested with prey or nonprey herbivores by a predatory mite," Journal of Chemical Ecology, vol. 30, no. 11, pp. 2215-2230, 2004.

[9] B. Y. Han and Z. M. Chen, "Behavior response of four Leis axyridis varieties to volatiles from tea and Toxoptera aurantii," Chinese Journal of Applied Ecology, vol. 11, no. 3, pp. 413-416, 2000.

[10] B. Y. Han and C. S. Zhou, "Attraction effect of main volatile components from tea shoots and flowers on Sphaerophoria menthastri (Diptera: Syrphidae) and Chrysopa septempunctata (Neuroptera: Chrysopidae)," Chinese Journal of Applied Ecology, vol. 15, no. 4, pp. 623-626, 2004.

[11] T. C. J. Turlings, J. H. Tumlinson, R. R. Heath, A. T. Proveaux, and R. E. Doolittle, "Isolation and identification of allelochemicals that attract the larval parasitoid, Cotesia marginiventris (Cresson), to the microhabitat of one of its hosts," Journal of Chemical Ecology, vol. 17, no. 11, pp. 22352251, 1991.

[12] T. C. J. Turlings, J. H. Loughrin, P. J. McCall, U. S. R. Rose, W. J. Lewis, and J. H. Tumlinson, "How caterpillar-damaged plants protect themselves by attracting parasitic wasps," Proceedings of the National Academy of Sciences of the United States of America, vol. 92, no. 10, pp. 4169-4174, 1995.

[13] T. C. J. Turlings and B. Benrey, "Effects of plant metabolites on the behavior and development of parasitic wasps," Ecoscience, vol. 5, no. 3, pp. 321-333, 1998.

[14] J. D. Allison and J. Daniel Hare, "Learned and naïve natural enemy responses and the interpretation of volatile organic compounds as cues or signals," New Phytologist, vol. 184, no. 4, pp. 768-782, 2009.

[15] R. Souissi, J. P. Nénon, and B. L. Rü, “Olfactory responses of parasitoid Apoanagyrus lopezi to odor of plants, mealybugs, and plant-mealybug complexes," Journal of Chemical Ecology, vol. 24, no. 1, pp. 37-48, 1998.

[16] R. Souissi and B. Le Rü, "Behavioural responses of the endoparasitoid Apoanagyrus lopezi to odours of the host and host's cassava plants," Entomologia Experimentalis et Applicata, vol. 90, no. 2, pp. 215-220, 1999.

[17] T. C. J. Turlings, J. H. Tumlinson, and W. J. Lewis, "Exploitation of herbivore-induced plant odors by host-seeking parasitic wasps," Science, vol. 250, no. 4985, pp. 1251-1253, 1990.
[18] M. Dicke, P. Van Baarlen, R. Wessels, and H. Dijkman, "Herbivory induces systemic production of plant volatiles that attract predators of the herbivore: Extraction of endogenous elicitor," Journal of Chemical Ecology, vol. 19, no. 3, pp. 581599, 1993.

[19] Y. G. Lou, X. Y. Hua, T. C. J. Turlings, J. A. Cheng, X. X. Chen, and G. Y. Ye, "Differences in induced volatile emissions among rice varieties result in differential attraction and parasitism of Nilaparvata lugens eggs by the parasitoid Anagrus nilaparvatae in the field," Journal of Chemical Ecology, vol. 32, no. 11, pp. 2375-2387, 2006.

[20] S. Takeshi, J. Takabayashi, W. Ashihara, and A. Takafuji, "Response of predatory insect Scolothips takahashii toward herbivore-induced plant volatiles under laboratory and field condition," Journal of Chemical Ecology, vol. 23, pp. 20332048, 1997.

[21] Y. P. Xie, J. L. Xue, X. Y. Tang, and S. L. Zhao, "The bunge prickly-ash tree damaged by a mealybug, Phenacoccus azaleae attracting the ladybug, Harmonia axyridis," Scientia Silvae Sinicae, vol. 40, pp. 116-122, 2004.

[22] J. D. Hare, "Ontogeny and Season Constrain the Production of Herbivore-Inducible Plant Volatiles in the Field," Journal of Chemical Ecology, vol. 36, no. 12, pp. 1363-1374, 2010.

[23] T. C. J. Turlings, U. B. Lengwiler, M. L. Bernasconi, and D. Wechsler, "Timing of induced volatile emissions in maize seedlings," Planta, vol. 207, no. 1, pp. 146-152, 1998.

[24] M. Dicke, R. Gols, D. Ludeking, and M. A. Posthumus, "Jasmonic acid and herbivory differentially induce carnivoreattracting plant volatiles in lima bean plants," Journal of Chemical Ecology, vol. 25, no. 8, pp. 1907-1922, 1999.

[25] Y. F. Zhang, Y. P. Xie, J. L. Xue, G. L. Peng, and X. Wang, "Effect of volatile emissions, especially $\alpha$-pinene, from persimmon trees infested by japanese wax scales or treated with methyl jasmonate on recruitment of ladybeetle predators," Environmental Entomology, vol. 38, no. 5, pp. 1439-1445, 2009. 

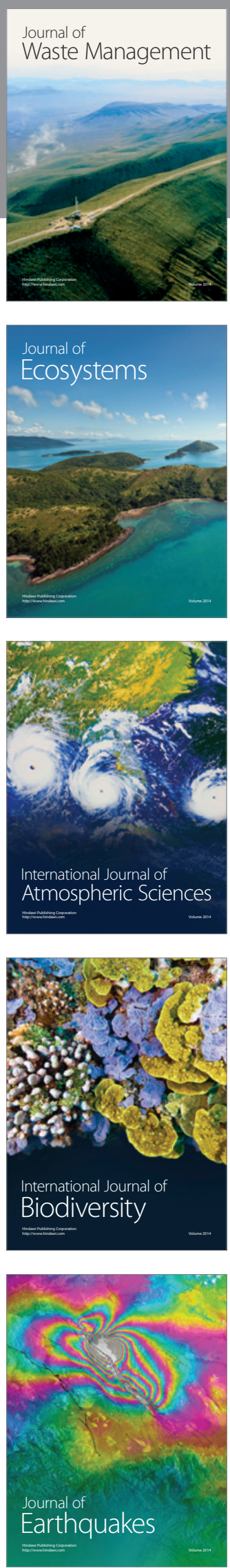
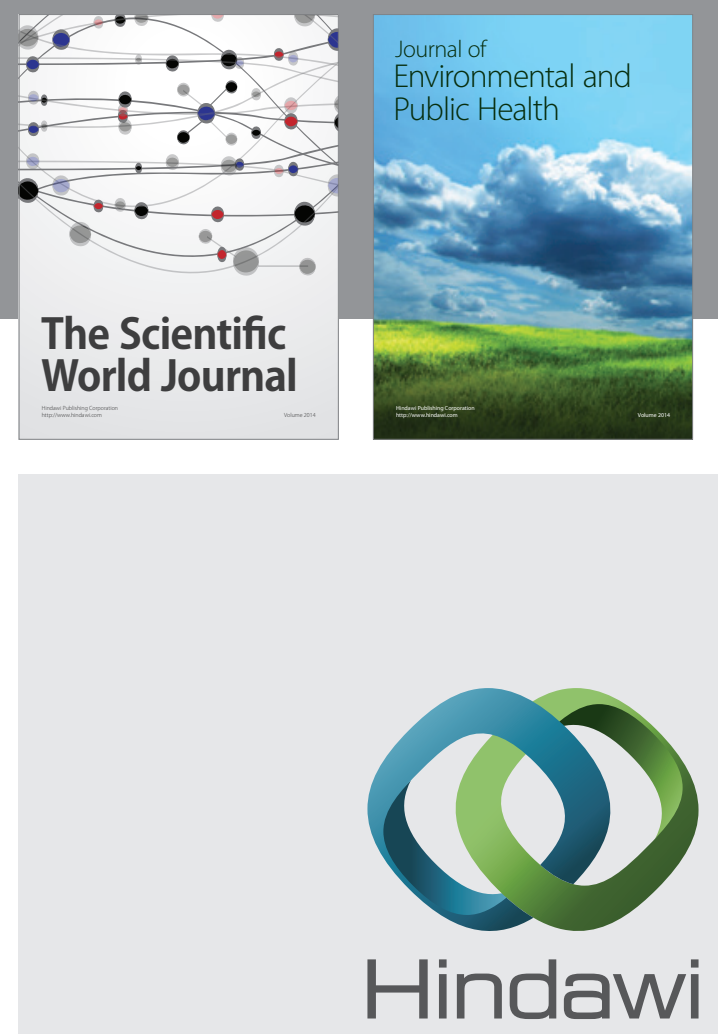

Submit your manuscripts at

http://www.hindawi.com
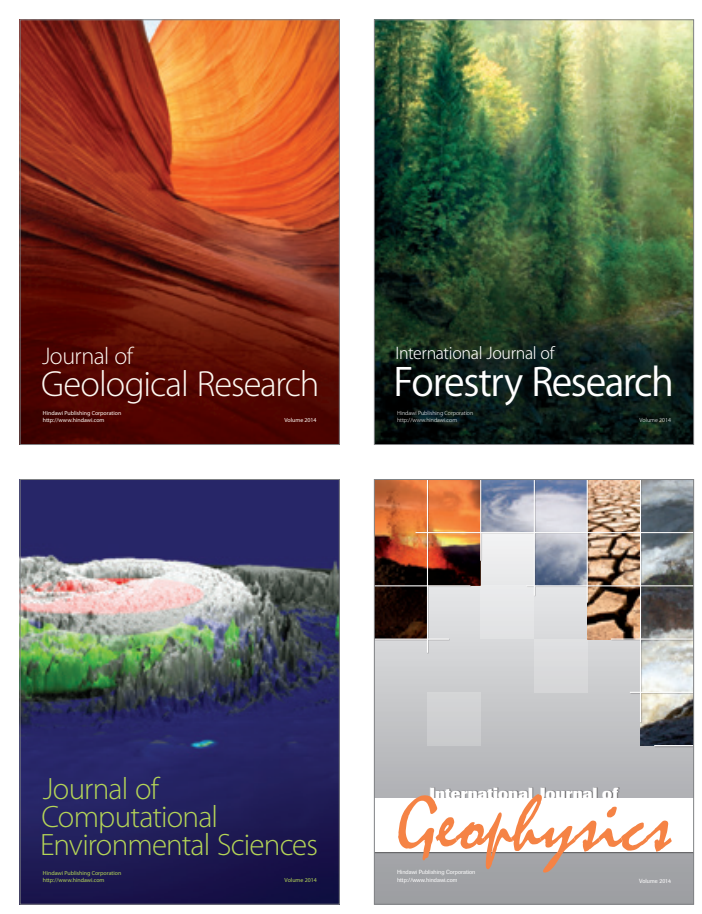
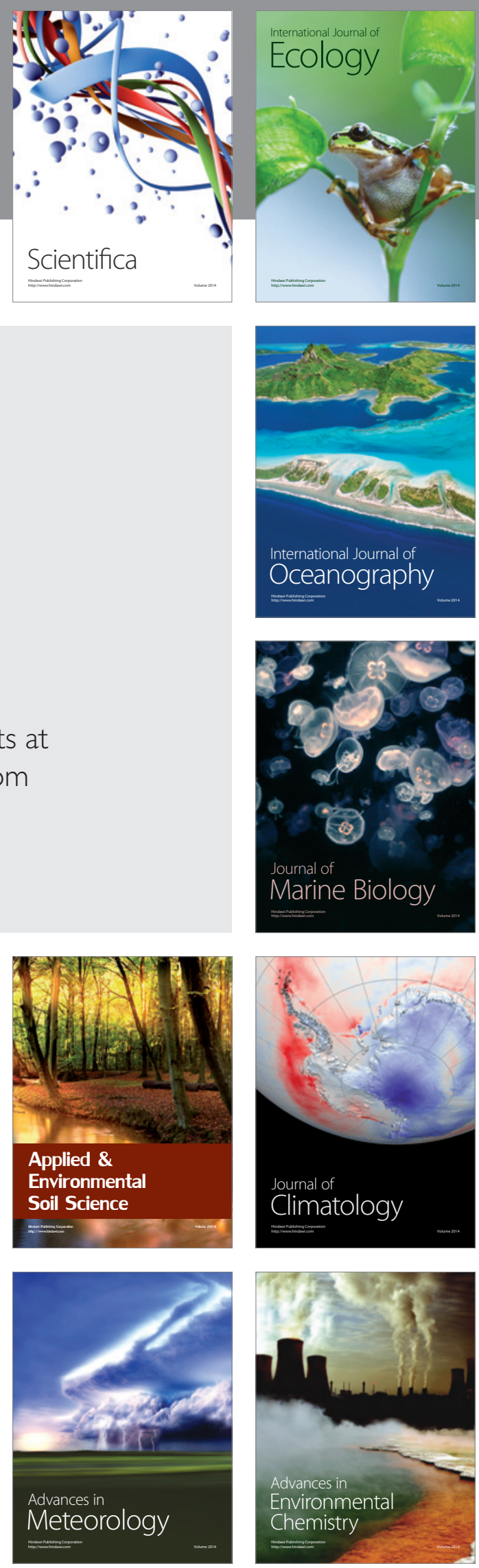